\title{
MARGINALIA. ALGUMAS NOTAS ADICIONAIS SOBRE O DOM
}

Pierre Bourdieu

A análise do dom que apresentei em Outline of a Theory of Practice e em The Logic of Practice (e que, para evitar repetições, dou por conhecida) se afasta das teorias anteriores, sobretudo da fenomenológica e da estruturalista, em três pontos fundamentais: leva em consideração o tempo ou, mais exatamente, o intervalo entre o dom e o contradom - e a incerteza; introduz uma teoria do agente e da ação que considera, como princípio da prática, as disposições constitutivas do habitus, e não a consciência ou a intenção; e remete a troca de dons a uma lógica muito particular, a da economia dos bens simbólicos e da crença específica (illusio) que a fundamenta.

O caráter primordial da experiência do dom é, sem dúvida, sua ambigüidade: de um lado, essa experiência é (ou pretende ser) vivida como rejeição do interesse, do cálculo egoísta, como exaltação da generosidade, do dom gratuito e sem retribuição; de outro, nunca exclui completamente a consciência da lógica da troca, nem mesmo a confissão de pulsões recalcadas ou, por éclairs, a denúncia de uma outra verdade, denegada, da troca generosa, seu caráter impositivo e custoso ("o presente é uma infelicidade"). Disso advém a questão, central, da dupla verdade do dom e das condições sociais que tornam possível o que pode ser descrito (de modo bastante inadequado) como uma self deception individual e coletiva, a mesma assinalada por Marcel Mauss em uma das frases mais profundas jamais escritas por um antropólogo: "A sociedade sempre paga a si mesma com a falsa moeda de seu sonho".

O modelo que propus leva em conta e explica a distância entre as duas verdades e, paralelamente, entre a visão que Lévi-Strauss, pensando em Mauss, chama de "fenomenológica"1 e a visão estrutural ou estruturalista: é o intervalo temporal entre o dom e o contradom que permite ocultar a contradição entre a verdade vivida (ou desejada) do dom como ato generoso, gratuito e sem retribuição, e a verdade que o modelo reve- 
la, aquela que faz do dom um momento de uma relação de troca transcendente aos atos singulares de troca. Ou seja, o intervalo que possibilita viver a troca objetiva como uma série descontínua de atos livres e generosos é o que torna psicologicamente viável e vivível a troca de dons, ao facilitar e favorecer a self deception, a mentira para si mesmo, condição da coexistência do conhecimento e do desconhecimento da lógica da troca.

É claro que a self deception individual só é possível porque está sustentada pela self deception coletiva: o dom é um desses atos sociais cuja lógica social não pode se tornar common knowledge, como dizem os economistas (uma informação é considerada common knowledge se todos sabem que todos sabem... que todos a possuem); ou, mais exatamente, é um common knowledge que não pode ser tornado público, um segredo de polichinelo, que não se pode tornar public knowledge, verdade oficial, publicamente proclamada (como, por exemplo, os grandes lemas republicanos). Essa self deception coletiva só é possível porque o recalque que existe em seu princípio (e cuja condição fenomenológica de possibilidade é justamente o intervalo temporal) está inscrito, a título de illusio, na base da economia dos bens simbólicos, essa economia antieconômica (no sentido restrito e moderno da palavra econômico) que se fundamenta na denegação (Verneinung) do interesse e do cálculo, ou, mais precisamente, em um trabalho coletivo de manutenção do desconhecimento, que tenta perpetuar uma fé coletiva no valor do universal, que nada mais é que uma forma de má-fé (no sentido sartreano de mentira para si mesmo) individual e coletiva. Este recalque está também inscrito em um investimento permanente em instituições que, como a troca de dons, produzem e reproduzem a confiança e, de modo mais profundo, a confiança no fato de que a confiança, isto é, a generosidade, a virtude, privada ou cívica, será recompensada. Ninguém ignora, de fato, a lógica da troca (ela aflora constantemente na explicitação quando se pergunta, por exemplo, se a dádiva será considerada suficiente), mas não existe ninguém que não se dobre à regra do jogo, que consiste em fazer de conta que se ignora a regra. Poder-se-ia falar de common miscognition para designar esse jogo no qual todos sabem - e não querem saber - que todos sabem - e não querem saber - a verdade da troca.

Se os agentes sociais podem, ao mesmo tempo, aparecer como enganadores e enganados, se parecem enganar os outros e enganar a si mesmos quanto às suas "intenções" (generosas), é porque seu embuste (que, em certo sentido, não engana ninguém) tem a certeza de contar com a cumplicidade tanto dos destinatários diretos de seu ato quanto dos que, 
como terceiros, o observam; e isso porque todos eles sempre estiveram inseridos em um universo social em que a troca de dons é instituída sob a forma de uma economia dos bens simbólicos. Essa economia muito especial se apóia, ao mesmo tempo, em estruturas objetivas específicas e em estruturas incorporadas, disposições, que essas estruturas pressupõem e produzem ao lhe oferecer suas condições de realização. Concretamente, isso significa que o dom como ato generoso só é possível para agentes sociais que adquiriram, em universos onde são esperadas, reconhecidas e recompensadas, disposições generosas adaptadas às estruturas objetivas de uma economia capaz de garantir-lhes recompensa (não apenas sob a forma de contradons) e reconhecimento, isto é, se cabe uma expressão na aparência tão redutora, um mercado. Essa economia dos bens simbólicos se apresenta, como toda economia, sob a forma de um sistema de probabilidades objetivas de lucro (positivo ou negativo) ou, para falar como Marcel Mauss, de um conjunto de "expectativas coletivas" com as quais se pode e se deve contar ${ }^{2}$. Em semelhante universo, quem dá sabe que seu ato generoso tem todas as chances de ser reconhecido como tal (em vez de parecer uma ingenuidade ou um absurdo) e de obter o reconhecimento (sob forma de contradom ou de gratidão) de quem foi beneficiado, sobretudo porque todos os outros agentes que participam desse mundo e que são moldados por essa necessidade também esperam que assim seja.

Em outros termos, no princípio da ação generosa, do dom inicial de uma série de trocas, não existe a intenção consciente (calculista ou não) de um indivíduo isolado, mas essa disposição do habitus que é a generosidade, e que tende, sem intenção explícita e expressa, à conservação ou ao aumento do capital simbólico. Assim como o sentido da honra (que pode estar no início de uma sucessão de assassinatos), essa disposição se adquire pela educação expressa (como no caso do jovem nobre evocado por Norbert Elias, que, quando devolve ao pai, intacta, a bolsa de dinheiro que recebera dele, vê este atirá-la pela janela), ou pela participação precoce e prolongada em universos onde ela é a lei indiscutível das práticas. Para quem é dotado de disposições ajustadas à lógica da economia dos bens simbólicos, o comportamento generoso não é o resultado de uma escolha ditada pela liberdade, de uma decisão livre efetuada após uma deliberação que contém a possibilidade de agir de outra forma; ele aparece como "a única coisa a fazer" 3.

É somente quando se abstrai a instituição - e o trabalho, sobretudo pedagógico, do qual ela é o produto - esquecendo-se de que quem dá e quem recebe estão preparados, por todo o trabalho de socialização, para 
entrar sem intenção nem cálculo de lucro na troca generosa, para conhecer e reconhecer o dom no que ele é, ou seja, em sua dupla verdade, que se tornam possíveis os paradoxos tão sutis quanto insolúveis de uma casuística ética. De fato, basta adotar o ponto de vista de uma filosofia da consciência, indagando-se sobre o sentido intencional do dom, e fazer uma espécie de "exame de consciência" digno do salos bizantino, que temia que suas ações mais santas fossem inspiradas pelos lucros simbólicos associados à santidade (cf. Dagron 1990), preocupado em saber se o dom, concebido como decisão livre de um indivíduo isolado, é um verdadeiro dom, é verdadeiramente um dom, ou, o que é a mesma coisa, se é conforme ao que o dom é em sua essência, isto é, no que ele tem para ser, para fazer surgir antinomias insuperáveis (o dom só é de fato dom se não parecer como tal, nem para quem o faz nem para quem o recebe) que obrigam a concluir que o dom gratuito é impossível. Mas, se é possível chegar a dizer que a intenção de dar destrói o dom, anula-o como tal, isto é, enquanto ato desinteressado, é porque, cedendo a uma forma particularmente aguda desse scholastic bias evocado por Austin e do erro intelectualista que o acompanha, se imagina os dois agentes envolvidos no dom como calculistas, cujo projeto subjetivo é fazer o que fazem objetivamente, segundo o modelo de Lévi-Strauss, ou seja, uma troca que obedece à lógica da reciprocidade. Em outras palavras, situa-se na consciência dos agentes o modelo que a ciência teve de construir para justificar sua prática (nesse caso, o da troca de dons). O que significa produzir uma espécie de monstro teórico, de fato impossível, a experiência autodestrutiva de um dom generoso, gratuito, que conteria o projeto consciente de obter o contradom (colocado como fim possível, futuro contingente) ${ }^{4}$.

Para se compreender adequadamente o dom, é indispensável afastar-se não só da filosofia da consciência, que considera como princípio de toda ação uma intenção consciente, mas também do economicismo que não conhece outra economia que a do cálculo racional e do interesse reduzido ao interesse econômico.

Entre as conseqüências do processo de constituição do campo econômico enquanto tal, uma das mais perniciosas, do ponto de vista do conhecimento, é a aceitação tácita de alguns princípios de divisão, cujo aparecimento é correlato à construção social do campo econômico como universo separado (com base no axioma "negócio é negócio"), princípios como a oposição entre as paixões e os interesses, que, por se imporem sub-repticiamente a todos os que estão imersos, desde o nascimento, nas frias águas da economia econômica, tendem a governar a ciência econômica, oriunda ela própria dessa separação ${ }^{5}$. 
A economia do dom, ao contrário da economia do "toma lá, dá cá", baseia-se em uma denegação do econômico (em sentido estrito), em uma recusa da lógica da maximização do lucro econômico, isto é, do espírito de cálculo e da busca exclusiva do interesse material (por oposição ao simbólico), que está inscrito na objetividade das instituições e nas disposições. Ela se organiza visando a acumulação do capital simbólico (como capital de reconhecimento, honra, nobreza etc.), que se efetua, sobretudo, através da transmutação do capital econômico realizada pela alquimia das trocas simbólicas (trocas de dons, de palavras, de desafios e réplicas, de mulheres etc.), e que só é acessível a agentes com disposições adaptadas à lógica do "desinteresse" (disposições que podem encontrar sua realização no "sacrifício supremo", aquele que consiste em "dar a própria vida", em preferir a morte à desonra - "é melhor morrer do que..." - ou, no contexto do Estado moderno, em "morrer pela pátria").

A economia do "toma lá, dá cá" é o produto de uma revolução simbólica que, nas sociedades européias, se realizou progressivamente, com, por exemplo, todos os processos insensíveis de desvelamento e de "desambigüização", dos quais o vocabulário das instituições indo-européias, analisado por Benveniste, conserva vestígios, e que levaram do resgate - do prisioneiro - à aquisição, do prêmio - por um feito relevante - ao salário, do reconhecimento moral ao reconhecimento de dívida, da crença ao crédito, da obrigação moral à obrigação jurídica diante de um tribunal. Essa "grande e venerável revolução", como diz Marcel Mauss, só pôde emergir da economia do dom - que Mauss assinala ser, "no fundo, na época, antieconômica" - pela progressiva suspensão da denegação coletiva dos fundamentos econômicos da existência humana (exceto em certos setores protegidos: a religião, a arte, a família) e por tornar, com isso, possível a emergência do puro interesse e a generalização do cálculo e do espírito de cálculo (estimulado pela invenção do trabalho assalariado e pelo uso da moeda). Assim, a possibilidade de submeter toda espécie de atividade à lógica do cálculo ("em negócios não há lugar para o coração") tende a legitimar essa espécie de cinismo oficial, que aparece sobretudo no Direito (por exemplo, nos contratos que prevêem as eventualidades mais pessimistas e inconfessáveis) e na teoria econômica (que contribuiu, originalmente, para fazer essa economia, como os tratados jurídicos sobre o Estado contribuíram para fazer o Estado). Essa economia, que se mostra eminentemente econômica porque, antes de tudo, permite economizar os efeitos da ambigüidade das práticas e dos "custos de transação" que tanto oneram a economia dos bens simbólicos (basta lembrar a diferença entre um presente personalizado, 
transformado assim em mensagem pessoal, e um cheque de valor equivalente), acaba por legitimar o uso do cálculo até nos domínios mais sagrados (le moulin à prières) e generalizar a disposição calculista, antítese perfeita da disposição generosa, que acompanha o desenvolvimento de uma ordem econômica e social caracterizada, como diz Weber, pela calculabilidade e previsibilidade.

A dificuldade particular que enfrentamos para pensar sobre o dom se deve ao fato de que, à medida que a economia do dom tende a se reduzir a uma ilhota no oceano da economia do "toma lá, dá cá", seu significado se altera (a tendência de certa etnografia colonial a considerá-la como uma mera forma de crédito é apenas o limite de uma propensão à redução etnocêntrica cujos efeitos são visíveis mesmo nas análises aparentemente mais reflexivas). Em um universo econômico fundado na oposição entre a paixão e o interesse (ou o amor desvairado e o casamento por interesse), entre o gratuito e o pago, o dom perde o seu verdadeiro sentido de ato situado para além da distinção entre a obrigação e a liberdade, a escolha individual e a pressão coletiva, o desinteresse e o interesse, para tornar-se uma simples estratégia racional de investimento orientada para a acumulação de capital social — com instituições como as relações públicas ou o brinde oferecido por empresas — - ou uma espécie de proeza ética impossível porque avaliada segundo o ideal do dom verdadeiro, entendido como ato perfeitamente gratuito e gracioso, ofertado sem obrigação ou expectativa, sem motivo ou finalidade, por nada.

Para eliminar definitivamente a visão etnocêntrica que está no princípio das indagações do economicismo, conviria examinar como a lógica da troca de dons leva a produzir relações duráveis, que as teorias econômicas baseadas em uma antropologia a-histórica não podem compreender. É notável que os economistas que redescobrem o dom (cf. Batifoulier, Cordonnier e Zenou 1992) esqueçam de colocar a questão das condições econômicas desses atos "antieconômicos" (no sentido restrito do adjetivo) e ignorem a lógica específica da economia das trocas simbólicas que os torna possíveis. É assim que, para explicar "como pode emergir a cooperação" entre indivíduos supostamente (por natureza) egoístas, "como a reciprocidade faz emergir a cooperação" entre indivíduos considerados - per definitionem - como "motivados apenas pelo interesse", "a economia das convenções", esta interseção vazia da economia com a sociologia, só pode invocar a "convenção", artefato conceitual que deve sem dúvida seu sucesso entre os economistas ao fato de que, como TychoBrahe tentando salvar o modelo ptolomaico por meio de remendos conceituais, ele permite evitar uma mudança radical de paradigma ("uma 
regularidade é uma convenção se todos se submetem a ela e esperam que os outros façam o mesmo"; "a convenção é o resultado de uma deliberação interior, que leva em conta regras de ação moral e regras de ação instrumental"). Essa virtude dormitiva não pode dar conta da coesão social, seja nas economias do dom, nas quais ela nunca se fundamenta exclusivamente na orquestração do habitus e sempre cede espaço a formas elementares de contrato, seja nas economias do "toma lá, dá cá", nas quais, embora se apóie amplamente nas injunções do contrato, se sustenta também amplamente na orquestração do habitus e em um acordo entre estruturas objetivas e estruturas cognitivas (ou disposições), que fundamenta a concordância das previsões individuais e a convergência das "expectativas coletivas".

A ambigüidade de uma economia orientada para a acumulação do capital simbólico decorre do fato de a comunicação, indevidamente privilegiada pelo olhar estruturalista, ser uma das vias de dominação. O dom expressa-se na linguagem da obrigação: obrigatório, ele obriga, produz pessoas obrigadas, "cria, como se costuma dizer, obrigações"; institui uma dominação legítima. Porque, entre outros motivos, ele institui o tempo, ao constituir o intervalo que separa o dom e o contradom (ou o assassinato e a vingança) como expectativa coletiva do contradom ou do reconhecimento, ou, de forma mais clara, como dominação reconhecida e legítima, como submissão aceita ou querida. É o que afirma La Rochefoucauld, cuja posição no limiar da economia do "toma lá, dá cá" e da economia do dom leva (como Pascal) a uma aguçada lucidez quanto às sutilezas, ignoradas pela etnologia estruturalista, da troca simbólica: "A pressa exagerada em cumprir uma obrigação é uma espécie de ingratidão". A pressa, sinal de submissão, torna-se, aqui, sinal de impaciência com a dependência e, por isso, quase ingratidão, pela premência demonstrada, pressa de desobrigar-se, de ficar quite, de ficar livre para quitar (sem se ver obrigado, como alguns khammès, a recorrer a uma fuga vergonhosa), de livrar-se de uma obrigação, de um reconhecimento de dívi$\mathrm{da}$; pressa de encurtar o intervalo de tempo que distingue a troca generosa de dons do brutal "toma lá, dá cá", e que determina que o sujeito fique obrigado, enquanto se sentir obrigado a retribuir, a reduzir a nada a obrigação que existe desde o instante em que o ato inicial de generosidade foi realizado, e que só pode crescer progressivamente à medida que o reconhecimento de dívida, sempre suscetível de ser resgatada, se transforme em reconhecimento incorporado, em inscrição nos corpos, sob a forma de paixão, de amor, de submissão, de respeito por uma dívida que não pode ser paga e, como se costuma dizer, é eterna. As relações de força 
simbólicas são relações de força que se instauram e se perpetuam por meio do conhecimento e do reconhecimento, o que não significa que isso se dê através de atos de consciência intencionais. Para que a dominação simbólica se institua, é preciso que os dominados compartilhem com os dominantes esquemas comuns de percepção e de apreciação através dos quais são percebidos por eles e os percebem, através dos quais eles se percebem como se os percebe; e que, dito de outra forma, seu conhecimento e reconhecimento encontrem seu princípio em disposições práticas de adesão e de submissão que, por não passarem pela deliberação e pela decisão, escapam à alternativa entre o consentimento e a coerção.

Estamos aqui no cerne da transmutação alquímica que se encontra no fundamento do poder simbólico como poder que se cria, se acumula e se perpetua através da comunicação, da troca simbólica. Porque, como tal, ela introduz na ordem do conhecimento e do reconhecimento (o que implica que ela só pode se realizar entre agentes capazes de se comunicar, de se compreender, ou seja, dotados dos mesmos esquemas cognitivos, e dispostos a comunicar-se, isto é, a reconhecer-se mutuamente como interlocutores legítimos, iguais em honra, a aceitar a interlocução, a estar in speaking terms) a comunicação que converte as relações de força bruta, sempre incertas e suscetíveis de serem suspendidas, em relações duráveis de poder simbólico pelas quais se é sujeitado ou às quais se sente sujeitado; ela transfigura o capital econômico em capital simbólico, a dominação econômica (do rico sobre o pobre, do patrão sobre o empregado, do homem sobre a mulher, do adulto sobre a criança etc.) em dependência pessoal (com o paternalismo, por exemplo), e mesmo em dedicação, piedade (filial) ou amor. A generosidade é possessiva e o será tanto mais quanto, nas trocas afetivas (entre pais e filhos, ou mesmo entre apaixonados), for e parecer mais sinceramente generosa ${ }^{6}$.

Aqui também o tempo tem um papel decisivo. O ato inaugural que institui a comunicação (ao dirigir a palavra, ao oferecer um dom, ao fazer um convite ou lançar um desafio etc.) tem sempre algo de intrusão ou até de questionamento (o que implica que seja feito com precauções interrogativas, como observou Bally: "posso tomar a liberdade de..."); além disso, ele sempre contém, queiramos ou não, a potencialidade de um constrangimento, de uma obrigação. Pode-se objetar que, ao contrário do que poderia sugerir o modelo mecânico dos estruturalistas, ele encerra uma incerteza, logo, uma abertura temporal: pode-se sempre optar por não responder à interpelação, ao convite ou ao desafio, ou por não responder de imediato, por adiar, por deixar na expectativa. Ocorre que a não-resposta é ainda uma resposta e que ninguém se livra com facilidade do 
questionamento inicial, que age como uma espécie de fatum, de destino: sem dúvida, o sentido da resposta positiva, réplica, contradom, objeção, é inequívoco como afirmação de reconhecimento da igualdade em honra (isotimia), que pode ser considerada como o ponto de partida de uma longa série de trocas; ao contrário, a ausência de resposta é essencialmente ambígua e pode sempre ser interpretada, por quem tomou a iniciativa da troca ou por terceiros, como uma recusa a responder e uma espécie de gesto de desprezo, ou como uma evasiva provocada pela impotência ou covardia, que lança na desonra.

Mas a incerteza, e mesmo a angústia ligada à antecipação do efeito do destino, não seriam tão fortes (sobretudo no dominado, por exemplo a mulher na relação de sedução) se a relação de comunicação que se instaura não contivesse sempre a potencialidade de uma relação de dominação. O caráter exótico dos objetos aos quais foram aplicadas as análises da troca, como o potlatch, levou a esquecer que as relações de troca na aparência mais gratuitas e menos onerosas - como a retribuição de solicitude, de gentilezas, de atenções ou de conselhos, sem mencionar os atos de generosidade irretribuíveis como a esmola —, quando se estabelecem em condições de assimetria durável (sobretudo porque aqueles que elas reúnem estão separados por defasagens econômicas ou sociais intransponíveis) que excluem a possibilidade de contrapartida, a própria esperança de uma reciprocidade ativa, condição de possibilidade de uma verdadeira autonomia, são de natureza a criar relações de dependência duráveis, variantes eufemizadas, pela subjetivação, da escravidão por dívida das sociedades arcaicas. Tendem, com efeito, a se inscrever nas dobras do corpo sob a forma de crença, de confiança, de afeição, de paixão, e qualquer tentativa para transformá-las pela consciência e pela vontade se choca com as resistências ocultas dos afetos e com as injunções tenazes da culpabilidade.

Embora na aparência tudo os oponha, o etnólogo estruturalista que considera a troca como princípio criador do vínculo social e o economista neomarginalista que se interroga desesperadamente sobre os princípios propriamente econômicos da cooperação entre agentes reduzidos ao estado de átomos isolados têm, como ponto comum, a ignorância das condições econômicas e sociais nas quais se produzem e reproduzem agentes históricos dotados (por seu aprendizado) de disposições duráveis que os tornam aptos e inclinados a entrar em trocas, iguais ou desiguais, geradoras de relações duráveis de dependência. Quer se trate da philia que regia, ao menos idealmente, as relações domésticas, ou da confiança concedida a uma pessoa ou a uma instituição (uma marca consagrada, por 
exemplo), essas relações de "confiança" ou de "crédito" não são necessariamente fundadas em e por um cálculo econômico racional (como se crê quando se procura explicar a confiança conferida às empresas mais antigas pela dimensão das adversidades que elas tiveram de superar) e sempre podem ser atribuídas à dominação durável que a violência simbólica assegura.

Seria preciso analisar aqui todas as formas de redistribuição, forçosamente ostentatórias, pelas quais indivíduos (quase sempre os mais ricos, é evidente, como no evergetismo grego analisado por Paul Veyne, ou a liberalidade de reis e príncipes), instituições, empresas (com suas grandes fundações) ou o próprio Estado tendem a instaurar relações assimétricas duráveis de reconhecimento (no duplo sentido do termo), fundadas no crédito concedido à filantropia. Seria preciso analisar, também, o longo processo pelo qual o poder simbólico, cuja acumulação se realiza primeiro em proveito de apenas uma pessoa, como no potlatch, deixa aos poucos de ser princípio de poder pessoal (através da apropriação pessoal de uma clientela, pela distribuição de dons, de prebendas, de cargos e de honrarias, como na monarquia absolutista), para tornar-se princípio de uma autoridade estatal, burocrática e impessoal, através da redistribuição burocrática que, embora obedecendo em princípio à regra "o Estado não dá nada de graça" (a pessoas privadas), não exclui completamente, pelo exercício da corrupção, formas de apropriação pessoal e de clientelismo.

Assim, através da redistribuição, o imposto entra em um ciclo de produção simbólica no qual o capital econômico se transforma em capital simbólico: como no potlatch, a redistribuição é necessária para garantir o reconhecimento da distribuição. Se ela tende evidentemente, como quer a leitura oficial, a corrigir as desigualdades da distribuição, tende também, e sobretudo, a produzir o reconhecimento da legitimidade do Estado.

O que é evocado através da troca de dons - essa falsa moeda de generosidade com a qual a sociedade se paga a si mesma, essa hipocrisia coletiva na qual e pela qual ela presta homenagem a seu sonho de virtude e desinteresse - é o fato de a virtude ser coisa política, que não é nem pode ser abandonada, a não ser pelo recurso a uma vaga "deontologia", aos esforços particulares e isolados das consciências e das vontades individuais, ou aos exames de consciência de uma casuística de confessor. A exaltação do êxito individual, de preferência econômico, que acompanhou a expansão do neoliberalismo, e que encontrou seus melhores defensores em alguns adeptos do socialismo, fez esquecer - nesta época em que, como que para se dar melhores meios de "culpar as vítimas", se 
tende mais do que nunca a formular em termos morais os problemas políticos - a necessidade de investir coletivamente nas instituições que produzem as condições econômicas e sociais da virtude ou, se se prefere, que fazem com que as virtudes cívicas de desinteresse e dedicação, como dom dirigido ao grupo, sejam estimuladas e recompensadas pelo grupo. É preciso substituir a questão puramente especulativa e tipicamente escolástica de saber se a generosidade e o desinteresse são possíveis, pela questão política dos meios que devem ser acionados para criar universos nos quais, como nas economias do dom, as pessoas estejam interessadas no desinteresse e na generosidade, ou melhor, estejam de modo duradouro predispostas ao respeito por essas formas universalmente respeitadas de respeito pelo universal.

Pierre Bourdieu ocupa a cadeira de Sociologia do Collège de France; é fundador e diretor de Actes de la Recherche en Sciences Sociales; e Diretor de Estudos da École des Hautes Études en Sciences Sociales. Entre seus últimos livros, estão Raisons Pratiques. Sur la Théorie de l'Action e, no Brasil, As Regras da Arte. Gênese e Estrutura do Campo Literário. 


\section{Notas}

1 Essa "fenomenologia" é muito imperfeita porque deixa escapar a ambigüidade e a dimensão temporal do dom. A respeito do que Lévi-Strauss entende por "fenomenologia" ou "fenomenológico", ver Lévi-Strauss (1950): "um dado puramente fenomenológico que a análise não consegue dominar" (:XXXV); "Toda a teoria exige assim a existência de uma estrutura da qual a experiência só oferece os fragmentos, os momentos dispersos, ou melhor, os elementos" (:XXXVIII); onde Lévi-Strauss censura Mauss por ter adotado uma espécie de fenomenologia espontânea do dom, a teoria indígena do hau, "forma consciente sob a qual os homens de determinada sociedade [...] apreenderam uma necessidade inconsciente, cuja razão está alhures" (:XXXIX).

2 Cf. M. Mauss (1974:II, 117): “Estamos entre nós, em sociedade, para esperarmos entre nós por este ou aquele resultado".

3 A todos que buscam no "dilema do prisioneiro" o princípio de todas as estratégias de cooperação, sugiro que imaginem que o que está em jogo não sejam desconhecidos indiferentes, mas os membros de uma mesma família em uma casa em chamas. Com isso quero dizer que nunca são preenchidas, na existência real, as condições econômicas e sociais que precisariam ser preenchidas para que um exercício lógico desse tipo fosse possível.

4 Através da questão do dom verdadeiro, do dom que é verdadeiramente dom (como no caso do verdadeiro respeito à regra, que exige que se vá além da regra), Jacques Derrida formula, em novos termos, a velha questão kantiana do dever e da possibilidade de detectar algum "impulso secreto do amor-próprio" por trás do maior sacrifício, aquele que se julga cumprir por puro dever, mas que é cumprido apenas de modo "conforme ao dever" (sobre o dom — verdadeiro como "dever além do dever", "lei" e "é preciso sem dever", ver Derrida (1991:197). A partir do momento em que se recusa como simplesmente "conforme à generosidade" qualquer ação generosa que tem por princípio uma disposição generosa, condenamo-nos a negar a possibilidade de uma ação desinteressada, da mesma forma que Kant, em nome de uma filosofia da consciência ou da intenção similar, não pode conceber uma única ação conforme ao dever que não possa ser suspeita de obedecer a determinações "patológicas" (cf. Derrida (1993:87-89)).

5 Sobre a separação que se efetua, nos séculos XVII e XVIII, entre as paixões e os interesses, ou os motivos exclusivamente econômicos, ver Hirschman (1977). É sem dúvida porque aceitam, sempre sem percebê-lo, essa oposição historicamente fundada, enunciada explicitamente na distinção fundadora de Pareto entre as ações lógicas e as ações não lógicas, "resíduos" ou "derivações", que os economistas tendem a se especializar na análise do comportamento motivado apenas pelo interesse: "muitos economistas [dizia Samuelson] tendem a diferenciar a 
economia da sociologia com base na distinção entre comportamento racional e irracional" (Samuelson 1947:90).

6 As crises, sempre particularmente trágicas, da economia do dom coincidem com a ruptura do encantamento que rebaixa a lógica da troca simbólica à ordem da troca econômica ("depois de tudo o que fizemos por você...").

\section{Referências bibliográficas}

BATIFOULIER, P., CORDONNIER, L. e ZENOU, Y. 1992. "L'Emprunt de la Théorie Économique à la Tradition Sociologique, le Cas do Don Contre-Don". Revue Économique, 5:917, 946.

DAGRON, G. 1990. "L'Homme sans Honneur ou le Saint Scandaleux". Annales ESC, julho/agosto. pp. 929-939. DERRIDA, J. 1991. Donner le Temps, 1, La Fausse Monnaie. Paris: Galilée. 1993. Passions. Paris: Galilée.
HIRSCHMAN, A. 1977. The Passions and the Interests. Princeton: Princeton University Press.

LÉVI-STRAUSS, Claude. 1950. "Introduction à l'Oeuvre de Marcel Mauss" . In: M. Mauss, Sociologie et Anthropologie. Paris: PUF.

MAUSS, Marcel. 1974. Oeuvres. Paris: Ed. de Minuit.

SAMUELSON, Paul. 1947. Foundations of Economical Analysis. Cambridge, Mass.: Harvard University Press. 
Resumo

Prosseguindo a análise do dom, este artigo busca ultrapassar as visões fenomenológica, estruturalista e economicista do fenômeno. Para tanto, desloca o eixo de interrogação na direção do tempo e da incerteza ligados ao intervalo entre o dom e o contradom, do agente e da ação ligados às práticas, da economia de bens simbólicos e o habitus específico que a funda. Demonstrase assim, contra todo reducionismo (à consciência, ao cálculo inconsciente ou ao cálculo propriamente dito), que a razão do dom só pode repousar sobre sua dupla verdade, seu caráter generoso e obrigatório. Por outro lado, demonstrase também que foi somente através de uma revolução simbólica, e não o desenvolvimento de uma suposta natureza humana, que uma economia da troca pôde, historicamente, se destacar da economia do dom, cuja possibilidade continua aberta, dependendo apenas dos investimentos coletivos que sejam efetuados em sua direção.

\section{Abstract}

Resuming an analysis of the gift, this article seeks to go beyond the phenomenological, structuralist, and economicist view of this phenomenon. It thereby shifts the trust of questioning towards the time and uncertainty linked with the interval between the gift and the counter-gift, the agent and the action linked to such practices, the economy of symbolic goods, and the specific habitus underlying it. It thus demonstrates against any and all reductionism (to consciousness, to unconcious calculation, and to calculation per se) that the gift's reason can only lie in its double truth, its generous and obligatory nature, both disinterested and interested. The author also demonstrates historically that it is only through a symbolic revolution, and not the development of a supposed human nature, that an economy of exchange can stand out from the economy of the gift, whose possibility remains open, requiring collective investments in its direction. 